\title{
Experimental Study on Water-Sand Seepage Characteristics in Fractured Rock Mass under Rheological Effect
}

\author{
Jiarui Chen $\left(\mathbb{D},{ }^{1}\right.$ Hai Pu $\mathbb{D},{ }^{2,3}$ Jianxiong Liu $\left(\mathbb{D},{ }^{1}\right.$ Jihua Zhang $\mathbb{D}^{1}$ Peitao Qiu ${ }^{1},{ }^{4}$ \\ Wenhu Gu $\left(\mathbb{1},{ }^{1}\right.$ Qirong Li $\left(\mathbb{0},{ }^{1}\right.$ and Zhendong Chen $\mathbb{1}^{1}$ \\ ${ }^{1}$ Faculty of Architecture and Civil Engineering, Huaiyin Institute of Technology, Huai'an, Jiangsu 223001, China \\ ${ }^{2}$ State Key Laboratory for Geomechanics \& Deep Underground Engineering, China University of Mining \& Technology, Xuzhou, \\ Jiangsu 221116, China \\ ${ }^{3}$ College of Mining Engineering and Geology, Xinjiang Institute of Engineering, Urumqi, Xinjiang 830091, China \\ ${ }^{4}$ School of Civil Engineering, Xuzhou University of Technology, Xuzhou, Jiangsu 221018, China
}

Correspondence should be addressed to Jianxiong Liu; 1011103615@qq.com

Received 24 February 2021; Accepted 13 August 2021; Published 21 August 2021

Academic Editor: Yi Xue

Copyright (c) 2021 Jiarui Chen et al. This is an open access article distributed under the Creative Commons Attribution License, which permits unrestricted use, distribution, and reproduction in any medium, provided the original work is properly cited.

\begin{abstract}
This study investigates water-sand bursting disasters associated with fractured rock that affect safe mining in the mining areas of Western China. A broken rock water-sand seepage rheological test device was developed, and rheological tests were conducted on multiple groups of broken rock samples with single-stage axial loading and different load levels. When the rheology of each group of broken rock samples was stable, water-sand mixed fluid was injected into the samples at a certain pressure gradient to conduct water-sand seepage tests on broken rock masses. It was found that when the porosity of a fractured rock mass is within a certain range, the water-sand mixed fluid does not completely pass through the fractured rock mass and some sand particles are filtered by the fractured rock sample. There is an exponential relationship between the sand breaking ability and the sand filtration ability of fractured rock and its initial porosity, and the permeability of fractured rock decreases by a certain extent after sand filtration. However, for different load levels, when the flow through a fractured rock mass tends to be stable, the final porosity of the fractured rock mass decreases exponentially with axial compression. Based on the classical Kelvin rheological model and the basic theory of fractional calculus, a new fractional rheological model has been proposed and the rheological parameters under different load levels were fitted to the model. The new fractional rheological model is better able to describe the rheological characteristics of broken mudstone.
\end{abstract}

\section{Introduction}

The removal of underground coal in China's western coal mining regions results in the formation of a goaf. Unsupported overburdened rocks undergo fractures that lead to interconnected cracks [1]. The seepage of mixed fluids formed by water and sand through the connected cracks within overburdened rocks can cause serious disasters from water and sand inrush [2], which seriously threaten production safety in western coal mines. The disasters caused by penetrating cracks are a threat to many projects $[3,4]$ and therefore a topic of intense research [5-11].

Backfilling of a goaf is currently considered to be the most effective manner to solve the problem of sedimenta- tion. Rheological effects are encountered due to loading compaction of broken rock that occurs during backfilling. The creep mechanical properties of saturated bulky gangue materials have been studied by other researchers [12]. However, several problems involving the long-term stability of backfill projects are related to the passage of time [13], which include the creep properties of the filling material under the long-term effect of loading. The water-bearing state of broken rock is an important factor that affects its creep mechanical properties, and major project accidents may occur due to the instability of loose rock that increases with time [14-17].

Significant progress has been made in the research on the rheological characteristics of various types of rocks $[18,19]$. However, most research has been conducted on whole-rock 
blocks [20] and research on the deformation characteristics of broken rock samples is lacking. Experimental research on creep has been conducted [21] on limestone rockfill material with a three-parameter model of rockfill material. When crushed rock is saturated with water, particle transfer and rearrangement occur due to external forces and the lubrication from water. Also, there are some differences between the rheological characteristics of saturated rock and dry rock. When rock particles are pushed against each other, they slide and deform to achieve a balance in the rheological process of the fractured rock. Rock particles are crushed directly due to external loads $[22,23]$, or smaller particles exit due to internal breakage or unstable crushing, which results in changes to the mechanical properties of broken rock. The changes in deformed seepage characteristics with time have been studied for broken sandstone [24], and unlike that of the entire rock blocks, the deformation scale of broken rocks under external forces is usually large. Also, changes in volume are much larger [25], resulting in changes in the porosity of broken rock and the surrounding rock space. These are crucial factors to consider [26] when addressing problems related to water and sand inrush in western coal mines. Physical quantities like elastic modulus and coefficient of viscosity of fractured rock change constantly during creep and compaction, and traditional rheological models are unable to fully describe such phenomena; the rheological equation of fractional calculus introduced in this study is well suited for the purpose.

The fractional-order system is a fundamental theory [27] that studies arbitrary order differentials and integrals. Integer-order differentials and integrals for arbitrary order extensions [28] in fractional calculus of mechanics are primarily applied in research on constitutive models of viscoelastic materials [29-31] and are currently one of the most active fields of research [32]. Kabwe et al. [33] proposed a fractional derivative viscoelastic (FDVP) constitutive model, which can estimate delayed deformation due to compression. Lokoshchenko et al. [34] considered the piecewiseconstant time dependence of bending moment magnitude and direction and used a linear fractional creep model to determine the fracture time of a plate. A new rheological parameter for fractional derivative models has been proposed [35] by combining drawing-fitting and numerical methods in terms of the viscoelastic properties of materials.

This paper considers that the seepage characteristics of water-sand mixtures in a fractured rock mass are affected by the compaction characteristics of fractured rock mass and the water pressure gradient. The elastic modulus and coefficient of viscosity change continuously during the process of compaction and rheology of fractured rock. However, the elastic modulus and viscosity coefficient are constants in traditional rheological models. Hence, using traditional models to describe the rheological properties of fractured rock masses results in large errors. This paper adopts the fractional parameter $\alpha$ to represent equivalent changes in the relationship between elastic modulus and coefficient of viscosity. It replaces a Newton dashpot with an Abel dashpot based on a saturated broken mudstone compaction rheological experiment, and a new rheological model is obtained via a fractional Kelvin model connected in series to a three-parameter model using a combination theory. Also, the water-sand seepage characteristics of broken rock due to rheological effects are studied based on the new model. This study provides a reference for safe mining in China's western coal mines.

\section{Test System and Solution}

2.1. Test System and Material. Lateral flow occurs readily in loosely confined, pressure-free crushed rocks under axial pressure that are therefore unable to bear large loads. However, in certain situations, such as in coal mines and tunnels, broken rocks bear both large and small confined pressures. Therefore, a broken rock rheology-water and sand seepage test device (Figure 1(a)) was designed for testing, using an MTS816 electrohydraulic servo-controlled test system (Figure 1(b)).

The broken rock samples were mudstone particles with particle diameters of $5 \sim 8,8 \sim 10,10 \sim 12,12 \sim 15$, and $15 \sim 20 \mathrm{~mm}$ evenly mixed with a ratio of $1: 1: 1: 1: 1$, and the density was $\rho=2420 \mathrm{~kg} / \mathrm{m}^{3}$ in the natural state. Sand in western mining areas is natural aeolian sand, with a particle size distribution of $20 \sim 220$ mesh. Each test used a total of $1200 \mathrm{~g}$ of broken rock, and $500 \mathrm{~g}$ of sand. The inner diameter of the cylinder was $100 \mathrm{~mm}$ with a height of $250 \mathrm{~mm}$.

2.2. Test Solution. A broken rock mass of mass $m$, fully moistened with water, was packed in the penetrator sleeve. Aeolian sand was then placed in the pressure-bearing ring and the sleeve was tapped lightly to compact the broken rock sample. The MTS816 was then started for loading, with the load being held at $0.05 \mathrm{kN}$ for 10 minutes to stabilize the system and set the initial state. A preset load $\sigma_{i}$ was then applied for the rheological test and the strain-stress curve of the broken rock was obtained. After a certain time $t_{\mathrm{i}}$, the deformation of the broken rock sample stabilized and the distance $h_{\mathrm{i}}$ between the piston and the lower permeable plate was measured, which represented the height of the broken mudstone sample and was used to calculate the porosity of the broken mudstone, as shown in equation (1) as follows:

$$
\phi_{i}=1-\frac{m}{\rho_{\text {mudstone }} r^{2} \pi h_{i}}(i=1,2,3,4),
$$

where $\phi_{i}$ is the porosity of broken mudstone at time $t_{\mathrm{i}}$ of the test; $m$ is the mass of the broken mudstone sample; $\rho_{\text {mudstone }}$ represents mudstone density; $r$ is the radius of the permeameter sleeve; $h_{\mathrm{i}}$ is the height of the mudstone test sample.

The pump was then switched on and water was pressurized to a certain pressure in the permeameter at which the deformation of the broken rock stabilized. The water-sand mixture formed when the water flow stirred up the sand particles inside the pressure-bearing ring via the broken rock, and seepage occurred. The sand particles were divided into three parts when the seepage was stable: one part $\left(m_{1}\right)$ infiltrated with the water flow; a second part $\left(m_{2}\right)$ resided within the broken rock due to the filtering of the broken rock framework; a third part $\left(m_{3}\right)$ remained within the 


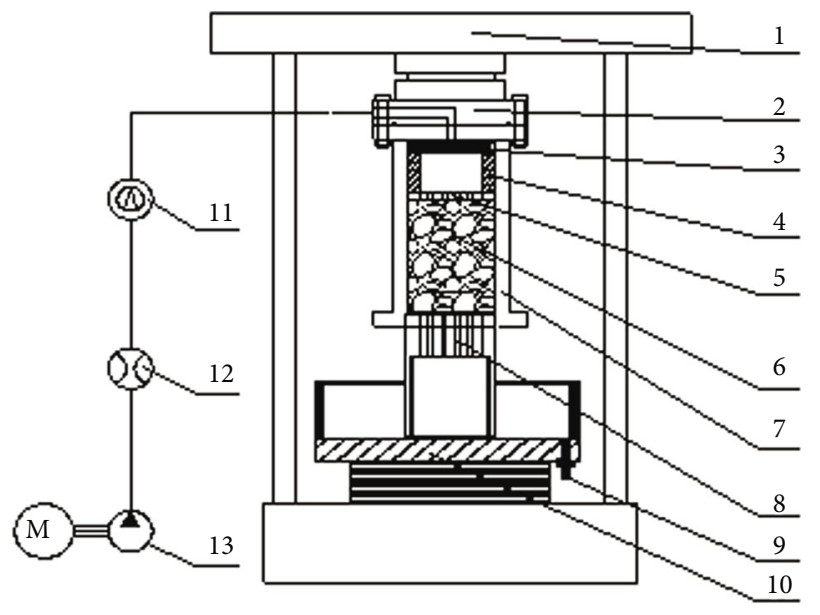

(a) Test system for rheology and seepage of broken rock

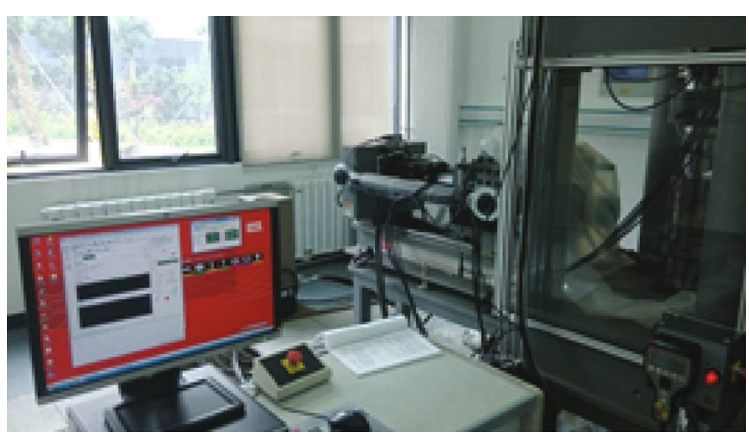

(b) MTS816 electrohydraulic servo-controlled test system

FIGURE 1: Test equipment. 1: MTS816; 2: permeameter base; 3: upper permeable plate; 4: pressure-bearing ring; 5: lower permeable plate; 6: broken rock; 7: permeameter sleeve; 8: piston; 9: tray outlet; 10: water-sand collection tray; 11: pressure gauge; 12: flowmeter; 13: speed regulation pump.

pressure-bearing ring. Among these, $m_{2}$ was the sand filtered by the broken rock and changed the porosity of the broken rock framework with the variation $\nabla \phi_{i}$ :

$$
\nabla \phi_{i}=\frac{m_{2}}{\rho_{\text {aeolian sand }} r^{2} \pi h_{i}},
$$

where $\rho_{\text {aeolian sand }}$ represents the aeolian sand density.

Here, the porosity of the broken rock framework is represented by $\varphi_{i}$ :

$$
\varphi_{i}=\phi_{i}-\nabla \phi_{i}(i=1,2,3,4) .
$$

In the test, the pressure differential of the seepage decreased linearly along the axial permeameter when the seepage stabilized. The outlet and inlet pressures $p$ were measured by the pressure gauge directly, and the outlet of the permeameter was connected to the atmosphere at pressure $p_{0}$. Hence, the formula for the pressure gradient $\Delta p$ is as follows:

$$
\Delta p=-\frac{\partial p}{\partial z}=\frac{p-p_{0}}{h_{i}}
$$

where $z$ is the direction of the pressure gradient.

The volume flow $(Q)$ through the permeameter per unit time was measured by the flowmeter and was used to calculate the speed of seepage $v$ :

$$
v=\frac{Q}{\pi r^{2}} .
$$

In the test, when the water-sand seepage occurred, some of the particles resided inside the broken rock framework due to the effect of filtering and changed the porosity of the broken rock framework. It was very difficult to dynamically observe the internal framework since the entire test sample was in a confined environment. The change in the porosity and framework structure of the broken rock sample led to changes in its seepage characteristics. This paper reports an investigation of the characteristics of permeability, porosity, water infiltration, water-sand seepage, and sand filtration of broken rock through an analysis of the various deformation processes of broken rock. The seepage process can be assumed to conform to the law of Darcy:

$$
-\frac{\partial p}{\partial z}=\frac{v \mu}{k}
$$

where $k$ is permeability and $\mu$ is the kinetic viscosity of the fluid.

\section{Analysis of the Rheological Characteristics of Broken Rock Based on the Fractional Calculus}

3.1. Curve of the Rheological Test of Broken Mudstone. Axial loads of $12,30,60$, and $120 \mathrm{kN}$ were successively applied on the samples during the tests, with the corresponding stresses being $1.53,3.82,7.64$, and $15.29 \mathrm{MPa}$. The corresponding heights at which the broken rock test samples for the above four loads stabilized rheologically were 119, 109, 101, and $94 \mathrm{~mm}$, respectively. Figure 2 shows the strain-stress curves of the broken mudstone test samples.

It was observed that rock particles pushed against each other, slid to deform, and achieved a balance during the rheological processes of fractured rock samples. Rock particles were crushed directly under the effect of external load, smaller particles exited due to internal breakage or unstable crushing, and particle transfer and rearrangement were enhanced under the joint effect of water lubrication and external force. Unlike entire-rock compression tests, the rheological parameters of broken rocks vary due to the above reasons. The rheological parameters of rocks under varying loads, however, can be presumed to be constant and equal 


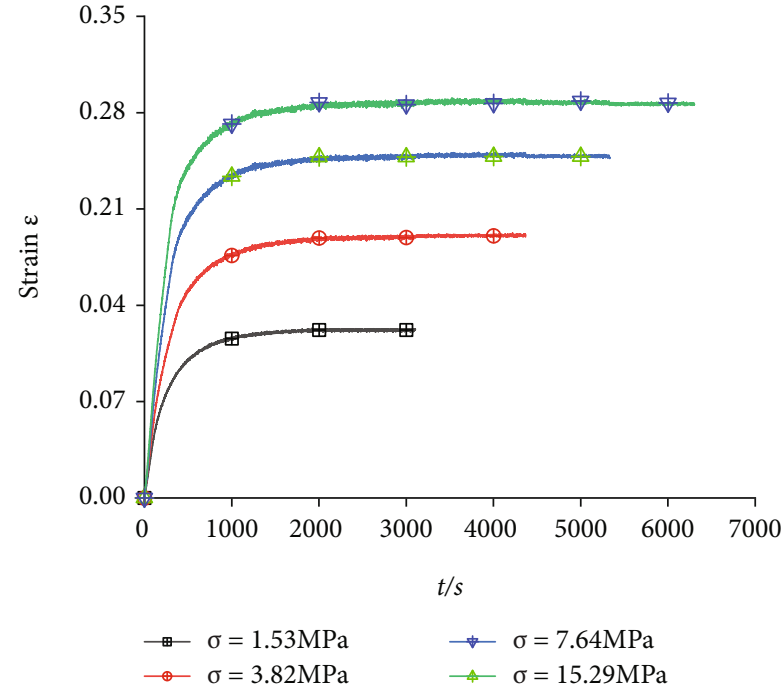

Figure 2: Test strain-time curves.

to the values obtained before crushing, for the entire-rock compression creeping test.

3.2. Basic Knowledge of Fractional Calculus. Among the many ways to define fractional calculus, the RiemannLiouville definition is the most common. For any complex $\alpha>0$, the integral fractional Riemann-Liouville definition is

$$
I_{a+}^{\alpha} f(t)=\frac{1}{\Gamma(\alpha)} \int_{a}^{t} \frac{f(\tau) d \tau}{(t-\tau)^{1-\alpha}}(t>a, \alpha>0),
$$

where $\Gamma(\alpha)=\int_{0}^{\infty} t^{\alpha-1} e^{-t} d t$ is the Gamma function. When $\alpha$ is an integer, the definition of fractional calculus and integer calculus is

$$
I_{a+}^{\alpha} f(t)=\frac{1}{(n-1) !} \int_{a}^{t} \frac{f(\tau) d \tau}{(t-\tau)^{1-n}}(n \in N)
$$

The fractional Riemann-Liouville definition has supersingularity which is inconvenient for engineering and physical modeling. An Italian geophysicist, Caputo, proposed a definition of weakly singular fractional differentials, for $0<$ $\alpha<1$, which is expressed as

$$
D_{t}^{\alpha} f(t)=\frac{1}{\Gamma(1-\alpha)} \int_{a}^{t} \frac{f^{\prime}(\tau) d \tau}{(t-\tau)^{\alpha}}(t>a) .
$$

The fractional derivative adopts the form $\left(d^{\alpha} / d t^{\alpha}\right) f(t)$ for practical applications.

3.3. Fractional Form of the Viscous Element. The Newton dashpot, when extended from the integer to fraction form, is known as the Abel dashpot (Figure 3). Its constitutive equation is stated as

$$
\sigma(t)=\eta^{\alpha} \frac{d^{\alpha} \varepsilon_{b}}{d^{\alpha} t} 0 \leq \alpha
$$

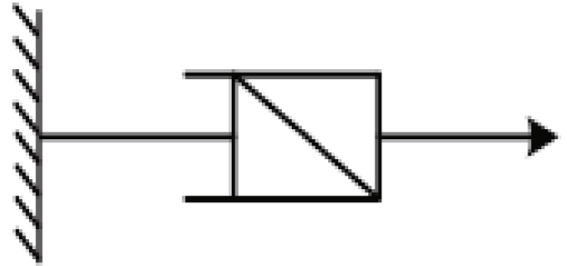

Figure 3: Abel dashpot.

Equation (10) may be rearranged as

$$
\frac{d^{\alpha} \varepsilon}{d^{\alpha} t}=\frac{\sigma(t)}{\eta^{\alpha}}
$$

where $\varepsilon$ is the strain on the viscous element and $\eta$ is the viscous coefficient.

When $\sigma(t)$ is constant, i.e., the stress is unchanged, the two sides of equation (11) for the fractional integral can be written per the operator theory of fractional calculus of Riemann-Liouville as

$$
J(t)=\frac{\varepsilon(t)}{\sigma}=\frac{1}{\eta^{\alpha}} \frac{t^{\alpha}}{\Gamma(1+\alpha)} .
$$

Equation (12) may be converted to a dimensionless form, from which the strain curve of the fractional Abel dashpot can be obtained (Figure 4).

When $\alpha=1$, the element represents an ideal fluid; when $\alpha=0$, it represents ideal elasticity. The Abel dashpot can represent the properties of both solids and fluids and can hence be used to study the mechanical properties of rheological rock.

3.4. A Constitutive Model of Fractional Rheology. Figure 5 shows a fractional rheological model based on the Kelvin model:

This model is based on a three-parameter model in series, i.e., a fractional Kelvin model with Abel dashpots (Figure 5). The Kelvin model with an integer solution alone does not agree well with experimental data at the initial stage of creep, resulting in errors. After the introduction of fractional orders, the model was able to solve this problem well.

The total strain of the model can be expressed as follows:

$$
\varepsilon=\varepsilon_{0}+\varepsilon_{1}+\varepsilon_{2}
$$

(1) Hooke's law for solids

$$
\varepsilon_{0}(t)=\frac{\sigma}{k_{0}}
$$

(2) Integer Kelvin model

$$
\sigma=k_{1} \varepsilon_{1}+\eta \dot{\varepsilon}_{1}
$$




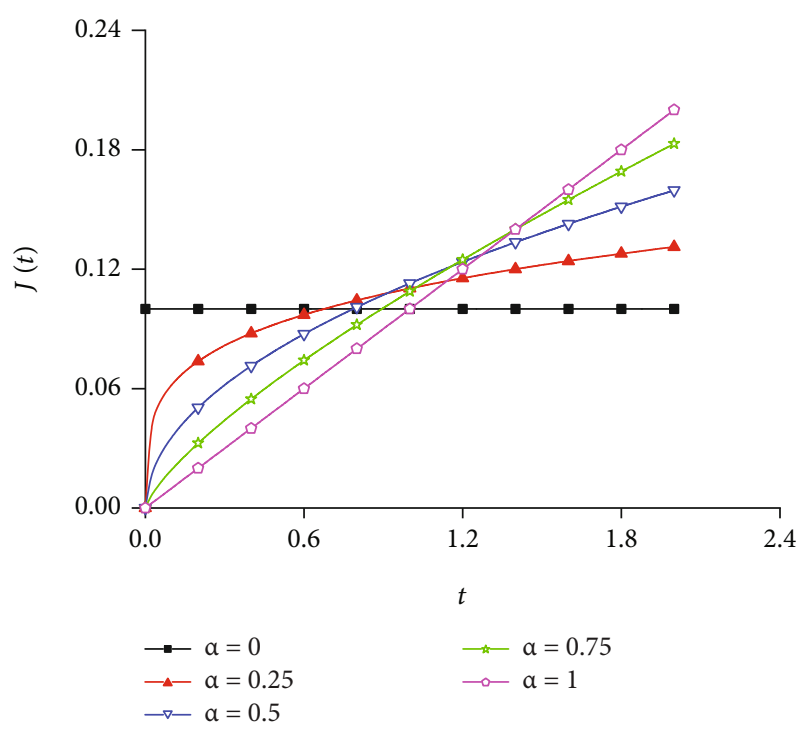

Figure 4: Strain characteristics of the Abel dashpot.

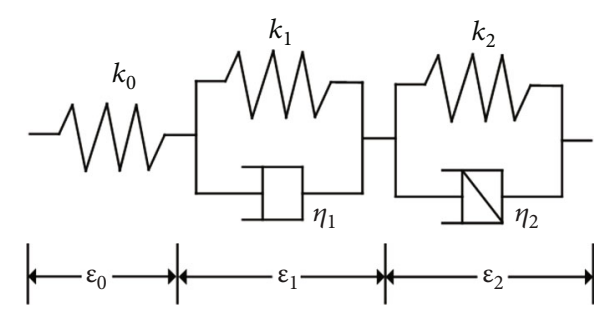

FIGURE 5: A fractional rheological model based on the Kelvin model.

$$
\varepsilon_{1}(t)=\frac{\sigma}{k_{1}}\left(1-e^{-t k_{1} / \eta_{1}}\right)
$$

(3) Fractional Kelvin model

$$
\sigma=k_{2} \varepsilon_{2}(t)+\eta \frac{d \varepsilon_{2}(t)}{d t}
$$

According to the basic theory of fractional calculus, assume that $a=k_{2} / \eta_{2}, b=\sigma / \eta_{2}$. At $t=0, \varepsilon_{2}=0$.

Equation (17) may then be written as follows:

$$
\frac{d^{\alpha} \varepsilon_{2}(t)}{d^{\alpha} t}+a \varepsilon_{2}(t)=b
$$

Applying a Laplace transform to equation (18) yields

$$
s^{\alpha} \varepsilon(s)+a \varepsilon(s)=\frac{b}{s} .
$$

The following equation is then obtained:

$$
\varepsilon(s)=\frac{b}{\left[s\left(s^{\alpha}+a\right)\right]} .
$$

An inverse Laplace transform on equation (20) yields

$$
\varepsilon_{2}(t)=b \int_{0}^{t}(t-s)^{\alpha-1} E_{\alpha, \alpha}\left[-a(t-s)^{\alpha}\right] \mathrm{d} s
$$

where $E_{\alpha, \beta}(z)=\sum_{n=0}^{\infty} z^{n} / \Gamma(n \alpha+\beta)$. Replacing $a, b$ in equation (21), the following equation is then obtained:

$$
\varepsilon_{2}(t)=\eta^{-1} \sum_{n=0}^{\infty} \frac{(-1)^{n}}{\Gamma(\alpha n+\alpha+1)}\left[\eta \frac{t^{\alpha}}{k}\right]^{n+1}
$$

Considering the three-part strain, the constitutive equation of the fractional rheological model can be expressed as

$$
\varepsilon(t)=\frac{\sigma}{k_{0}}+\frac{\sigma}{k_{1}}\left(1-e^{-t k_{1} / \eta_{1}}\right)+\eta^{-1} \sum_{n=0}^{\infty} \frac{(-1)^{n}}{\Gamma(\alpha n+\alpha+1)}\left[\eta \frac{t^{\alpha}}{k}\right]^{n+1} .
$$

3.5. Analysis of the Experimental Results of Broken Mudstone Based on the New Fractional Rheological Model. To study the rheological characteristics of saturated broken mudstone and validate the accuracy of the new fractional rheological model, the 1stOpt mathematical software is applied to fit the parameters according to the data obtained from the experiment. The fitting effect is shown in Figure 6, based on the fractional rheological model (equation (23)).

It can be seen in Figure 6 that the fitting accuracy between the theoretical and experimental values is high. The fitting parameters are shown in Table 1.

Broken mudstone has remarkable creep characteristics, which can cause substantial changes in porosity and permeability. It is an important parameter that affects the safety of coal mining.

Porosity refers to the ratio of the pore volume and the total volume of the particles in the broken state:

$$
n=\frac{V_{s}-V}{V_{s}}
$$

where $n$ is the porosity; $V$ is the particle volume of the broken rock sample; $V_{s}$ is the total volume of the broken rock sample in the test. In this paper, the variation of the porosity of broken mudstone in a stable state of deformation for different levels of pressure is shown in Figure 7. 


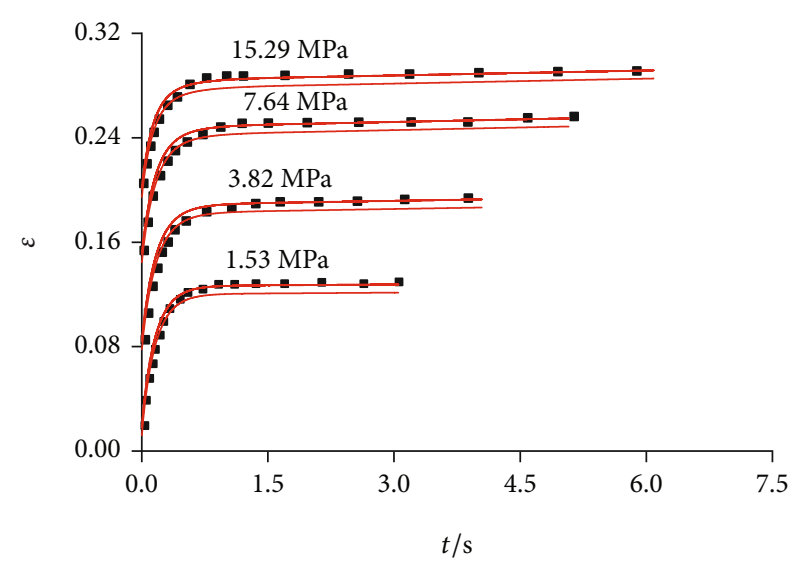

- Experimental data

- Fitting curve

FIGURE 6: Rheological model fitting curve obtained from test results.

TABle 1: Parameters of new fractional model.

\begin{tabular}{lcccc}
\hline Axial compression $(\mathrm{MPa})$ & 1.53 & 3.82 & 7.64 & 15.29 \\
\hline$k_{0}(\mathrm{MPa})$ & 58.60 & 12.10 & 6.67 & 5.21 \\
$k_{1}(\mathrm{MPa})$ & 10.70 & 12.30 & 13.8 & 18.40 \\
$k_{2}(\mathrm{MPa})$ & 58.55 & 36.89 & 33.22 & 29.34 \\
$\eta_{1}\left(10^{3} \mathrm{~s} \cdot \mathrm{MPa}\right)$ & 1.80 & 2.08 & 2.20 & 2.40 \\
$\eta_{2}\left(10^{3} \mathrm{~s} \cdot \mathrm{MPa}\right)$ & 1.90 & 2.00 & 2.22 & 2.82 \\
$\alpha$ & 0.78 & 0.81 & 0.82 & 0.79 \\
\hline
\end{tabular}

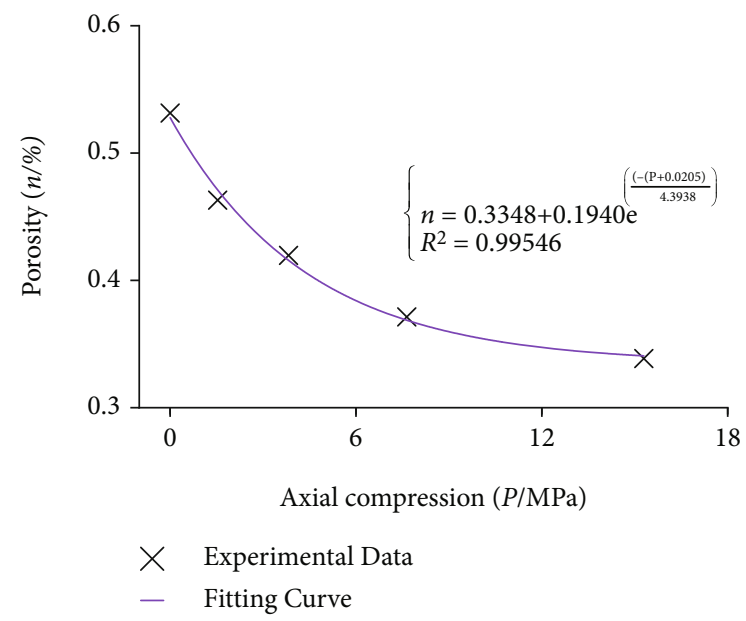

FIgure 7: Porosity curve.

By fitting the data of steady-state porosity changes for different levels of pressure, the equation of the porosity curve is obtained as follows:

$$
n=a \cdot e^{b \cdot P}+c
$$

TABLE 2: Water and sediment seepage test data of broken rock samples under different loads.

\begin{tabular}{lcccc}
\hline Stress level $(\mathrm{MPa})$ & Initial porosity & $v(\mathrm{~mm} / \mathrm{s})$ & $m_{1}(\mathrm{~g})$ & $m_{2}(\mathrm{~g})$ \\
\hline 1.53 & 0.263 & 4.69 & 42 & 112 \\
3.82 & 0.296 & 4.71 & 65 & 111 \\
7.64 & 0.331 & 4.78 & 106 & 109 \\
15.29 & 0.374 & 4.96 & 161 & 103 \\
\hline
\end{tabular}

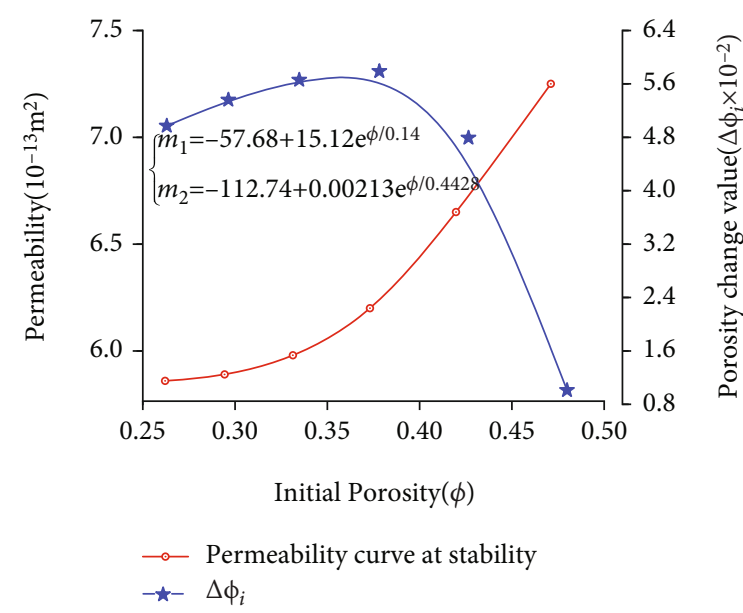

Figure 8: Relationship between initial porosity and seepage characteristics under axial loading.

where $n$ is porosity; $P$ is the axial pressure; parameters $a$, $b$, and $c$ are constants, where $a=0.193, b=-0.228$, and $c=0.335$.

\section{Water-Sand Seepage Characteristics of Fractured Rock due to Rheological Effects}

The porous characteristics of a fractured rock skeleton are the basic factors that determine its permeability. According to the different heights, $h_{i}$, of the broken rock samples, the pump speed was adjusted and the water pressure $P$ was changed to maintain the water pressure gradient $\Delta p$ at $8 \times$ $10^{-3} \mathrm{MPa} / \mathrm{mm}$. The test data is shown in Table 2 .

During the water and sediment seepage test, the porosity of broken rock changed due to filtration and the barrier effect of the broken rock skeleton. When the water and sediment seepage was stable, the masses of permeable sand particles $\left(m_{1}\right)$ and filtered sand particles $\left(m_{2}\right)$ were different for broken rock skeletons with different initial porosities. Figure 8 shows the relationship between the final porosity and permeability when the water-sand seepage was stable.

It can be seen in Figure 8 that water and sand seepage reduced the permeability of the fractured rock samples. When the initial porosity of the fractured rock was small, the change in porosity was large. In other words, sand particles may play a role in filling voids, thus reducing the possibility of a large-scale water inrush. When the initial porosity 
increased to a certain value, the porosity variation $\nabla \phi_{i}$ tended to be 0 , the broken rock lost the ability to filter sand, and almost all sand particles exited the broken rock. Under these conditions, there was a great risk of water inrush and sand break.

When a steady seepage state was reached, the framework of the broken rock was filled with sand particles. It can be seen in Figure 8 that with an increase in initial porosity, the filtration quality of a broken rock sample decreased and the permeability increased. The relationship between the initial porosity and the quality of sand burst and filtration can be expressed by an exponential function (equation (26)):

$$
\begin{aligned}
& m_{1}=-57.68+15.12 e^{\phi / 0.14}, \\
& m_{2}=-112.74-0.00213 e^{\phi / 0.04428} .
\end{aligned}
$$

\section{Conclusion}

In this paper, an experimental study on the water-sand seepage characteristics of fractured rock under rheological action was conducted:

(1) Creep-time characteristic plots were obtained by conducting axial compression experiments on several groups of broken mudstone samples. During compaction of saturated broken rock samples, particle crushing and sliding deformations were encountered. During the compaction rheological process, the elastic modulus and viscosity coefficient of the samples changed continuously and the deformation characteristics were quite different from those of whole-rock compression. In this paper, a fractionalorder parameter $\alpha$ was used to equivalently represent the continuous changes in the elastic modulus and viscosity coefficient. Based on fractional calculus and a three-parameter model, a fractional Kelvin model was connected in series with an Abel dashpot to form a new rheological model

(2) Creep data of broken mudstone under different pressures were obtained from axial compression tests of several groups of broken rock samples. The parameters of the new fractional rheological model were fitted using 1stOpt software, by inputting the creep parameters of broken mudstone samples under different pressures. Compared with the three-parameter model, the fitting accuracy of the fractional rheological model was higher. From the rheological data of broken mudstone samples, the values of the stable porosities of broken mudstone under various pressures were determined and the relationship between pressure and porosity was obtained by fitting the test data

(3) When the rheological tests of each group of broken rock were stable, a water pressure gradient of $8 \times 10^{-3} \mathrm{MPa} / \mathrm{mm}$ was applied to the permeameter using a pump for each sample. The watersand mixed fluid percolated through the broken rock samples, and the value of permeability obtained was
$10^{-13} \mathrm{~m}^{2}$. However, sand particles could not completely pass through the broken rock samples. Some sand particles were filtered and intercepted by broken rock and became part of the broken rock sample, thus changing its porosity and permeability. An exponential relationship between the initial porosity and the quality of sand burst and filtration was thereby obtained. This study guides the risk prediction and assessment of water and sand inrush in broken rock

\section{Data Availability}

The data used to support the findings of this study are included within the article.

\section{Conflicts of Interest}

The authors declare that they have no conflicts of interest.

\section{Acknowledgments}

This work was supported by the National Natural Science Foundation of China (nos. 51904113, U1803118, 51974296, and 51904112) and the 2019 Huaishang Talent Plan Program.

\section{References}

[1] H. Zhang, M. Tu, H. Cheng, and Y. Tang, "Breaking mechanism and control technology of sandstone straight roof in thin bedrock stope," International Journal of Mining Science and Technology, vol. 30, no. 2, pp. 259-263, 2020.

[2] Y. Wang, F. Geng, S. Yang, H. Jing, and B. Meng, "Numerical simulation of particle migration from crushed sandstones during groundwater inrush," Journal of Hazardous Materials, vol. 362, pp. 327-335, 2019.

[3] G. Zhang, Y. Jiao, H. Wang, Y. Cheng, and L. B. Chen, "On the mechanism of inrush hazards when Denghuozhai Tunnel passing through granite contact zone," Tunnelling and Underground Space Technology, vol. 68, pp. 174-186, 2017.

[4] L. Huang, J. Ma, M. Lei, L. Liu, Y. Lin, and Z. Zhang, "Soilwater inrush induced shield tunnel lining damage and its stabilization: a case study," Tunnelling and Underground Space Technology, vol. 97, p. 103290, 2020.

[5] G. Zhang, Y. Jiao, C. Ma, H. Wang, L. B. Chen, and Z. C. Tang, "Alteration characteristics of granite contact zone and treatment measures for inrush hazards during tunnel construction - a case study," Engineering Geology, vol. 235, pp. 64-80, 2018.

[6] D. Zhang, X. Xie, M. Zhou, Z. K. Huang, and D. M. Zhang, "An incident of water and soil gushing in a metro tunnel due to high water pressure in sandy silt," Engineering Failure Analysis, vol. 121, p. 105196, 2021.

[7] K. Xia, C. Chen, Y. Zheng et al., "Engineering geology and ground collapse mechanism in the Chengchao Iron-ore Mine in China," Engineering Geology, vol. 249, pp. 129-147, 2019.

[8] G. Zhang, C. Wang, Y. Jiao, H. Wang, and L. B. Chen, "Deposits sources of inrush hazards for the Liangshan Tunnel passing through deeply buried granite," Tunnelling and Underground Space Technology, vol. 92, p. 103058, 2019.

[9] L. Yu, C. Zhanqing, L. Shuncai, D. Feng, and Z. Lianying, "Experimental study on influence of the creeping of saturated 
rock to mechanical properties [J]," Mining Research \& Development, vol. 31, no. 6, pp. 51-52, 2011.

[10] M. Li, J. X. Zhang, X. X. Miao, and Y. L. Huang, "Strata movement under compaction of solid backfill body [J]," Journal of China University of Mining \& Technology, vol. 43, no. 6, pp. 969-973, 2014.

[11] Y. Y. Wang, J. Qi, C. H. Yang, and J. Wei, “A study of nonlinear creep law in deep rocks [J]," Rock and Soil Mechanics, vol. 26, no. 1, pp. 117-121, 2005.

[12] Y. Xue, T. Teng, F. Dang, Z. Ma, S. Wang, and H. Xue, "Productivity analysis of fractured wells in reservoir of hydrogen and carbon based on dual-porosity medium model," International Journal of Hydrogen Energy, vol. 45, no. 39, pp. 20240-20249, 2020.

[13] Y. Xue, P. G. Ranjith, F. Dang et al., "Analysis of deformation, permeability and energy evolution characteristics of coal mass around borehole after excavation," Natural Resources Research, vol. 29, no. 5, pp. 3159-3177, 2020.

[14] G. He, E. Wang, and X. Liu, "Modified governing equation and numerical simulation of seepage flow in a single fracture with three-dimensional roughness," Arabian Journal of Geosciences, vol. 9, no. 1, 2016.

[15] X. Liu, S. Wang, S. Wang, and E. Wang, "Fluid-driven fractures in granular materials [J]," Bulletin of Engineering Geology and the Environment, vol. 77, pp. 621-636, 2015.

[16] X. L. Liu and S. Y. Wang, "Mine water inrush forecasting during the mining under waters [J]," Disaster Advances, vol. 5, no. 4, pp. 877-882, 2012.

[17] Y. L. Chen and R. Azzam, "Creep fracture of sandstones [J]," Theoretical and Applied Fracture Mechanics, vol. 47, no. 1, pp. 57-67, 2007.

[18] Y. Xin, M. Li, D. An, H. Ji, and J. Kang, "Experimental study on the instability mechanism of the major-defect fractured rock [J]," Arabian Journal of Geosciences, vol. 10, no. 14, pp. 1-12, 2017.

[19] O. Hamza and R. Stace, "Creep properties of intact and fractured muddy siltstone," International Journal of Rock Mechanics and Mining Sciences, vol. 106, pp. 109-116, 2018.

[20] F. Wu, H. Zhang, Q. Zou, C. Li, J. Chen, and R. Gao, "Viscoelastic-plastic damage creep model for salt rock based on fractional derivative theory," Mechanics of Materials, vol. 150, p. 103600, 2020.

[21] Z. Shen and Z. Kuizhi, "Back analysis of creep deformation of rockfill dams [J]," Journal of Hydraulic Engineering, vol. 6, pp. 1-6, 1998.

[22] Y. Xue, J. Liu, P. G. Ranjith, X. Liang, and S. Wang, "Investigation of the influence of gas fracturing on fracturing characteristics of coal mass and gas extraction efficiency based on a multi-physical field model," Journal of Petroleum Science and Engineering, vol. 206, p. 109018, 2021.

[23] L. Zhu, F. Dang, Y. Xue, K. Jiao, and W. Ding, "Multivariate analysis of effects of microencapsulated phase change materials on mechanical behaviors in light-weight aggregate concrete," Journal of Building Engineering, vol. 42, p. 102783, 2021.

[24] S. C. Li, Z. Q. Chen, X. X. Miao, and Y. Liu, "Experimental study on the properties of time-dependent deformationseepage in water-saturated broken sandstone [J]," Journal of Mining \& Safety Engineering, vol. 28, no. 4, pp. 542-547, 2011.
[25] L. Shuncai, C. Zhanqing, and Y. Liu, "Study on penetration features of coal rejects during constant load deformation test process [J]," Coal Science and Technology, vol. 41, no. 3, pp. 59-62, 2013.

[26] S. Wanghua, C. Guangtao, and Q. Dong, "Experimental research on critical percolation gradient of quicksand across overburden fissures due to coal mining near unconsolidated soil layers [J]," Chinese Journal of Rock Mechanics and Engineering, vol. 26, no. 10, pp. 2084-2091, 2007.

[27] R. Garra, F. Mainardi, and G. Spada, "A generalization of the Lomnitz logarithmic creep law via Hadamard fractional calculus [J]," Chaos, Solitons \& Fractals, vol. 102, pp. 333-338, 2017.

[28] L. Zhuo and B. Xu, "Finite element method for viscoelastic fractional derivative model [J]," Engineering Mechanics, vol. 18, no. 3, pp. 40-44, 2001.

[29] Y. Feng, X. Yang, J. Liu, and Z. Q. Chen, “A new fractional Nishihara-type model with creep damage considering thermal effect," Engineering Fracture Mechanics, vol. 242, p. 107451, 2021.

[30] M. di Paola, L. Galuppi, and G. Royer Carfagni, "Fractional viscoelastic characterization of laminated glass beams under time- varying loading," International Journal of Mechanical Sciences, vol. 196, p. 106274, 2021.

[31] F. Wu, R. Gao, J. Liu, and C. Li, "New fractional variable-order creep model with short memory," Applied Mathematics and Computation, vol. 380, p. 125278, 2020.

[32] X. Xu and Z. Cui, "Investigation of a fractional derivative creep model of clay and its numerical implementation," Computers and Geotechnics, vol. 119, p. 103387, 2020.

[33] E. Kabwe, M. Karakus, and E. K. Chanda, "Creep constitutive model considering the overstress theory with an associative viscoplastic flow rule," Computers and Geotechnics, vol. 124, p. 103629, 2020.

[34] A. M. Lokoshchenko and L. V. Fomin, "Delayed fracture of plates under creep condition in unsteady complex stress state in the presence of aggressive medium," Applied Mathematical Modelling, vol. 60, pp. 478-489, 2018.

[35] T. Beda and Y. Chevalier, "New methods for identifying rheological parameter for fractional derivative modeling of viscoelastic behavior [J]," Mechanics of Time-Dependent Materials, vol. 8, no. 2, pp. 105-118, 2004. 